\title{
Impact of a Faculty Development Course on Promotion at a Health Sciences Center
}

\author{
Sanja Kupesic Plavsic, MD, PhD', Valerie Osland Paton, $\mathrm{PhD}^{2}$, Christiane \\ Herber-Valdez, EdD ${ }^{3}$, Consuelo Rosales, BS ${ }^{4}$, Martin D. Garcia, MS5, and \\ Zuber D. Mulla, PhD, CPH ${ }^{1}$
}

Author affiliations are listed at the end of this article.

Corresponding author: Zuber D. Mulla, PhD, CPH Paul L. Foster SOM, Texas Tech University Health Sciences Center zuber.mulla@ttuhsc.edu

\section{KEYWORDS}

Continuing medical education, Faculty development, Promotion, Longitudinal data analysis, Generalized estimating equations.

\section{METHODS}

A retrospective cohort study (October 2008-October 2019) was conducted using publicly available faculty data. A total of 148 IFDC graduates were compared to 87 non-graduates. Subjects were full-time assistant professors at Texas Tech University Health Sciences Center El Paso at the start of follow-up. The binary outcome was promotion to associate professor. The outcome was measured annually from 2008 to 2019. Follow-up ended when the faculty member left our institution, was promoted to associate professor, or the study ended, whichever came first. Longitudinal data analysis was performed using generalized estimating equations (GEE) logistic regression with an independent working correlation structure. Adjusted odds ratios (OR) for promotion were calculated from the GEE logistic regression model.

\section{RESULTS}

The 235 faculty members contributed a total of 1015 records. The average ages (standard deviation) of IFDC graduates and non-graduates were 40.7 (8.6) and 40.3 (7.4) years, respectively.
More than half of the IFDC graduates were female $(54.1 \%)$, and $44.8 \%$ of the non-graduates were female. A positive association was detected between IFDC status (graduates vs. nongraduates) and being promoted to associate professor after controlling for time, age, sex, race and Hispanic ethnicity, discipline/specialty, and tenure track status in a GEE logistic regression model: adjusted $\mathrm{OR}=11.68,95 \%$ confidence interval: $2.72-50.21, P=0.001$.

\section{CONCLUSIONS}

Completion of the IFDC was strongly correlated with promotion to associate professor at our health sciences center.

\section{INTRODUCTION}

Evaluating the effect of faculty development programs on professional success is an important task of any academic health sciences center. ${ }^{1}$ Do these programs produce effective educators, leaders, and scholars? Steinert and colleagues conducted a systematic review of faculty development initiatives that were designed to improve teaching effectiveness. ${ }^{2}$ Focusing 
on professional development initiatives that targeted basic science and clinical faculty working in medicine, their review of 111 studies found improvement in both self-reported and observed teaching practices.

Armstrong and Barsion used an outcomes logic model to evaluate a faculty development program targeted to medical educators. ${ }^{3}$ They interviewed 16 individuals who had participated in the Harvard Macy Program for Physician Educators. Thirteen of the interviewees noted increased knowledge about using learnercentered teaching methods. The same number of respondents reported a stronger commitment to the discipline of medical education. Medical school faculty are also interested in the longterm outcomes of professional development programs. Results from Armstrong and Barsion's study further suggest that the number of promotions among graduates of the Harvard Macy Program for Physician Educators would be a valuable long-term performance metric.

Faculty development professionals have recently focused on the importance of resiliency. Gheihman et al. created two exercises to equip faculty with the skills needed to promote resilience among medical students. ${ }^{4}$ They conducted train-the-trainer workshops at two medical education conferences during which international faculty were taught these two exercises. Participants rated the workshops on a five-point Likert scale ( $1=$ lowest; 5 =highest). Data from both workshops were combined for analysis. The authors reported an average score of 4.8 for overall quality.

Faculty development programs frequently target the improvement of research skills. Chavda and colleagues implemented a structured, handson mentoring model at their medical school in Gujarat, India. ${ }^{5}$ The goal of this program was to train faculty members in the area of research. Their study included a total of eight early and mid-career faculty members. Their development program consisted of two modules, one of which focused on the drafting of a protocol while the other centered on manuscript writing. Participants expressed an overall favorable change in their attitude towards research and reported an improvement in their research skills.

Wolfe et al. addressed the challenge of increasing research productivity in a primarily communitybased setting by creating an annual research symposium. ${ }^{6}$ The target audience was hospital faculty and trainees. These authors found that during the first four years of their symposium, abstract submissions increased from 29 to greater than 50, and the number of IRB-approved research projects rose from 65 to 123 .

While faculty development programs have been shown to improve teaching performance and other critical skills, their association with promotion remains unclear. Guevara et al. conducted an analysis of the Association of American Medical Colleges (AAMC) Faculty Roster in order to determine if minority faculty development programs were associated with various outcomes, including recruitment and promotion at 124 US medical schools. ${ }^{7}$ Guevara and colleagues did not detect a relationship between the presence of a faculty development program targeted to underrepresented minority faculty and the outcome of promotion among this group of faculty: adjusted odds ratio $(\mathrm{OR})=1.08,95 \%$ confidence interval $(\mathrm{CI}): 0.91$ -1.30 . However, to maintain confidentiality in this study, faculty members were deidentified and hence these investigators did not have the ability to follow faculty members from year to year within their institutions and monitor the retention or promotion status of these individual faculty.

Texas Tech University Health Sciences Center EI Paso (TTUHSC EP) is composed of a medical school, nursing school, graduate school of biomedical sciences, and a dental school. The Office of Faculty Development at TTUHSC EP administers the Institutional Faculty Development Course (IFDC). The IFDC was started in 2003 and except for two instances, it has been held once a year since its inception (In 2004 two cohorts graduated, and in 2008 the IFDC was not offered). ${ }^{8}$ While graduation from the IFDC is not a prerequisite for the submission of an application for tenure or promotion, all newly hired junior faculty members are encouraged to attend the IFDC soon after joining the institution. IFDC participants are nominated by their department chairs. Evolving over the years, our IFDC is targeted to junior and mid-level faculty and focuses on enhancing their teaching and assessment skills, developing their scholarship, and establishing their network of colleagues. The eight-month course is offered once a year.

The ability of faculty development programs 
to change attitudes and skills has been demonstrated in the literature. ${ }^{9}$ However, individual-level data from long-term studies of the association between participation in institutional professional development programs and the probability of being promoted at a health sciences center are lacking. To address this gap in knowledge, we conducted a longitudinal study to examine if a relationship exists between graduation from our IFDC and promotion to associate professor.

\section{METHODS}

Our study protocol was submitted to the Institutional Review Board (IRB) for the Protection of Human Subjects at TTUHSC EP and was deemed exempt from formal IRB review (IRB \# E20124).

\section{DESCRIPTION OF THE IFDC}

The IFDC is offered once per year and is about eight months in length. The course offers approximately 80 hours of material $(40$ hours required to graduate).$^{10}$ The curriculum consists of four domains: teaching, scholarship/ research, clinical skills/simulation (for practicing clinicians), and leadership development. Given the historic focus at our institution on clinical service and education, the main goal of the IFDC has been the development of effective faculty educators. Participants attended weekly fourhour workshops. Workshops were planned by the Office of Faculty Development approximately one year in advance. A variety of topics were traditionally addressed in these workshops, such as adult learning strategies, delivering feedback to learners, library skills, study design, sample size calculations, and conflict resolution. In addition to lectures and hands-on workshops, health care providers enrolled in the IFDC were offered a rich selection of simulation modules to enhance their skills as a clinical simulation educator. IFDC participants were required to deliver two oral presentations to their IFDC cohort members. These presentations were evaluated by a panel of judges and the remaining IFDC participants.

IFDC workshops and lectures were supplemented with one-hour Need to Know grand rounds. ${ }^{10}$ The Need to Know quarterly grand round series allowed the Office of Faculty Development to rapidly insert timely topics of interest to faculty in the curriculum. All of the IFDC sessions/activities were open to every faculty member, including our university's community faculty and faculty members who are not enrolled in the IFDC.

\section{SOURCE OF DATA AND INCLUSION CRITERIA}

A retrospective cohort study was conducted using individual-level data contained in our institution's annual faculty report (CBM008) to the Texas Higher Education Coordinating Board. These data are managed by the TTUHSC EP Office of Institutional Research and Effectiveness, are collected each year using a consistent methodology based on CBM008 reporting guidelines and definitions and are publicly available. The Office of Faculty Development maintains a database of IFDC graduates. For the purpose of our longitudinal study, annual data on all faculty members who graduated from the IFDC between 2003 and 2019 were linked to the CBM008 faculty report dataset. CMB008 data are not available prior to October 1, 2008.

The study period was October 1, 2008, to October 1, 2019. Faculty members were included in our longitudinal study if they were at the rank of assistant professor and were full-time employees at the start of follow-up. The cohort was open (dynamic); that is, faculty members who were appointed to our institution's full-time faculty body after October 1, 2008, were eligible to join the cohort as long as they were at the rank of assistant professor.

\section{DATA ANALYSIS}

Data were analyzed using SAS 9.4 software (SAS Institute, Inc., Cary, North Carolina). The binary exposure (independent) variable was graduation from the IFDC between 2003 and 2019. This exposure was a time-dependent (time-varying) variable. IFDC graduates were compared to a random sample of non-graduates. The CBM008 dataset contained 497 non-graduates at the time we began our investigation. A simple random sample of 200 individuals was selected from the sampling frame of these 497 faculty members 
who did not graduate from the IFDC (Figure 1). Follow-up did not begin in 2003 because, as stated above, CMB008 data were not available until October 1, 2008. Baseline differences in demographic characteristics were tested for statistical significance using the chi-square test and two-sample $t$-test as appropriate.

The outcome in our study was promotion to associate professor. A longitudinal data analysis was performed. The binary exposure variable (IFDC graduation status) and the binary outcome (associate professor vs. assistant professor) were measured once a year on Oct. 1, as was the faculty member's age. Follow-up ended when the faculty member was promoted to associate professor, separated from our institution, or the study ended (whichever came first). The unadjusted incidence (probability) of being promoted was plotted over time for the IFDC graduates and non-graduates. Generalized estimating equations (GEE) were used to account for the statistical dependence among the repeated measurements within subjects. ${ }^{11}$, ${ }^{12} \mathrm{GEE}$ logistic regression models were fit using the GENMOD Procedure and the REPEATED statement. Several working correlation structures were explored with the final choice being an independent working correlation matrix. ${ }^{13-15}$

The following variables were included in the GEE logistic regression model in addition to the IFDC graduation status variable: the year of observation, the faculty member's age, sex, race and Hispanic ethnicity, tenure track category, and discipline/specialty. Given the small number of faculty members who were Black or Native Hawaiian/Pacific Islander, these two categories were combined into one group for the logistic regression analysis. The logistic regression model assumes that the logit varies in a linear fashion with the predictor. Inspection of a logit plot revealed a non-linear association between the faculty member's age and the natural logarithm of the odds of being promoted (the logit), and hence age was dichotomized: $\geq 40$ vs. $<40$ years.

A three-level discipline/specialty variable was created using the information in the CBM008 dataset: medical school faculty member in a clinical department, medical school faculty member in a non-clinical department (Department of Medical Education or the Department of Biomedical Sciences), and nursing school faculty member. Initially, this three-level categorical variable was included in our full GEE logistic regression model using two dummy variables. However, the estimation routine failed. This was most likely due to the small number of outcome events (promotions) relative to the number of independent variables that were included in the model. Given this challenge, the discipline/specialty variable was collapsed into a binary variable: medical school faculty member in a non-clinical department compared to other faculty (medical school faculty in a clinical department or nursing school faculty). Our dataset did not have information on the faculty member's academic degrees such as MD/DO only, MD/DO plus a master's degree, etc.

An additional GEE logistic regression model containing an IFDC-by-year interaction term was created; however, our final model did not include this product interaction term for several reasons. First, an inspection of the temporal trend in the probability of promotion indicated that an interaction term was unnecessary. Second, the interaction term was not statistically significant $(P=0.64)$. Third, the inclusion of this interaction term resulted in an extreme and implausible estimate of the IFDC graduation parameter and its standard error in the GEE logistic regression model. Finally, a comparison of the QIC from a model with an IFDC-by-year interaction term with the QIC from a model without this interaction term indicated that the final GEE logistic regression model should not include this interaction term. QIC is a goodness of fit statistic for GEE models.

Adjusted ORs, 95\% Cls, and $P$-values were reported from the final GEE logistic regression model. If the $95 \% \mathrm{CI}$ for the population OR excluded 1, then the result was considered to be statistically significant.

\section{RESULTS}

The electronic records of 415 faculty members were evaluated for inclusion in our study with the final sample size being 235 (Figure 1). Characteristics of the study subjects at the start of follow-up are reported in Table 1. The number of IFDC graduates varied across time; that is, faculty were allowed to cross over from the non-graduate group to the graduate group after completion of the IFDC. The maximum number of IFDC graduates and non-graduates in 
the cohort were 148 and 87 , respectively (Table 1). Before 2010, the size of each graduating class of the IFDC ranged from two to six faculty members, and from 2010 through 2019, the class size varied from 10 to 15 faculty members (data not shown). Over half of the IFDC graduates (54.1\%) were female (Table 1). Overall, the largest three racial groups were Hispanics, followed by Whites, and then Asians. Statistically significant unadjusted associations were detected between the IFDC graduation status and the following two variables: discipline/ specialty of the faculty member and tenure track status. The number of promotions was 34 among IFDC graduates and two among the nongraduates.

The time trend in the probability of being promoted to associate professor (expressed as a percent) is shown in Figure 1. In 2018, 13 of

TABLE 1. Characteristics of 235 individuals who were full-time assistant professors at TTUHSC El Paso at the start of follow-up, 2008-2019. Faculty who graduated from any of the Institutional Faculty Development Courses (IFDC) were compared to those who did not graduate from the IFDC.

\begin{tabular}{|c|c|c|c|}
\hline Characteristic & $\begin{array}{c}\text { IFDC } \\
\text { Graduate } \\
\mathrm{N}=148\end{array}$ & $\begin{array}{c}\begin{array}{c}\text { Non- } \\
\text { Graduate }\end{array} \\
\quad \mathrm{N}=87\end{array}$ & $\boldsymbol{P}$ \\
\hline \multicolumn{4}{|l|}{ Age in years at baseline } \\
\hline Mean (standard deviation) & $40.7(8.6)$ & $40.3(7.4)$ & 0.70 \\
\hline Age $\geq 40, \mathrm{n}(\%)$ & $68(46.0)$ & $39(44.8)$ & 0.87 \\
\hline Sex, n (\%) & & & 0.17 \\
\hline Female & $80(54.1)$ & $39(44.8)$ & \\
\hline Male & $68(46.0)$ & $48(55.2)$ & \\
\hline Race-ethnicity, n (\%) & & & 0.47 \\
\hline Asian & $32(21.6)$ & $25(28.7)$ & \\
\hline Black non-Hispanic & $9(6.1)$ & $2(2.3)$ & \\
\hline Hispanic & $59(39.9)$ & $31(35.6)$ & \\
\hline Native Hawaiian or Pacific Islander & $1(0.7)$ & $0(0.0)$ & \\
\hline White & $47(31.8)$ & $29(33.3)$ & \\
\hline Discipline/Specialty & & & 0.005 \\
\hline Medical school clinical department & $121(81.8)$ & $81(93.1)$ & \\
\hline Medical school non-clinical department ${ }^{\dagger}$ & $23(15.5)$ & $2(2.3)$ & \\
\hline Nursing faculty & $4(2.7)$ & $4(4.6)$ & \\
\hline Tenure track status & & & 0.0003 \\
\hline Not tenure track & $124(83.8)$ & $86(98.9)$ & \\
\hline Tenure track & $24(16.2)$ & $1(1.2)$ & \\
\hline Number promoted to associate professor & $34^{t}$ & $2 \ddagger$ & - \\
\hline
\end{tabular}

tDepartment of Biomedical Sciences or the Department of Medical Education.

tPercentages are not shown since the number of IFDC graduates and non-graduates under observation varied over time (see Figure 2 and Results).

mds.marshall.edu/mjm

(C) 2021 Marshall Journal of Medicine
Marshall Journal of Medicine Volume 7 Issue 2 
FIGURE 1. Study Enrollment

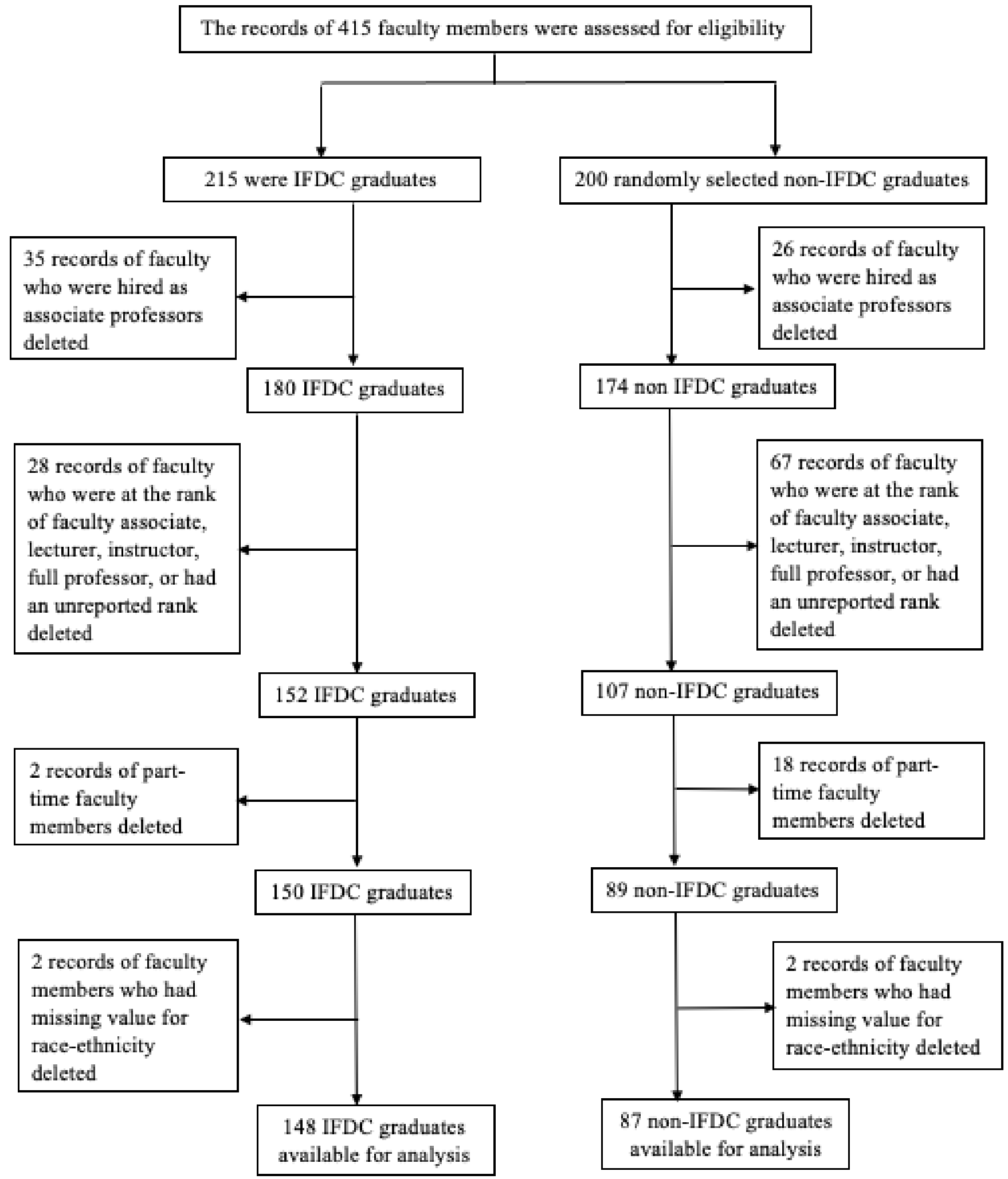


FIGURE 2. Time trend in the probability of promotion from assistant professor to associate professor (expressed as a percent) among full-time faculty members from October 1, 2008 to October 1, 2019. Graduates of the Institutional Faculty Development Course were compared to non-graduates.

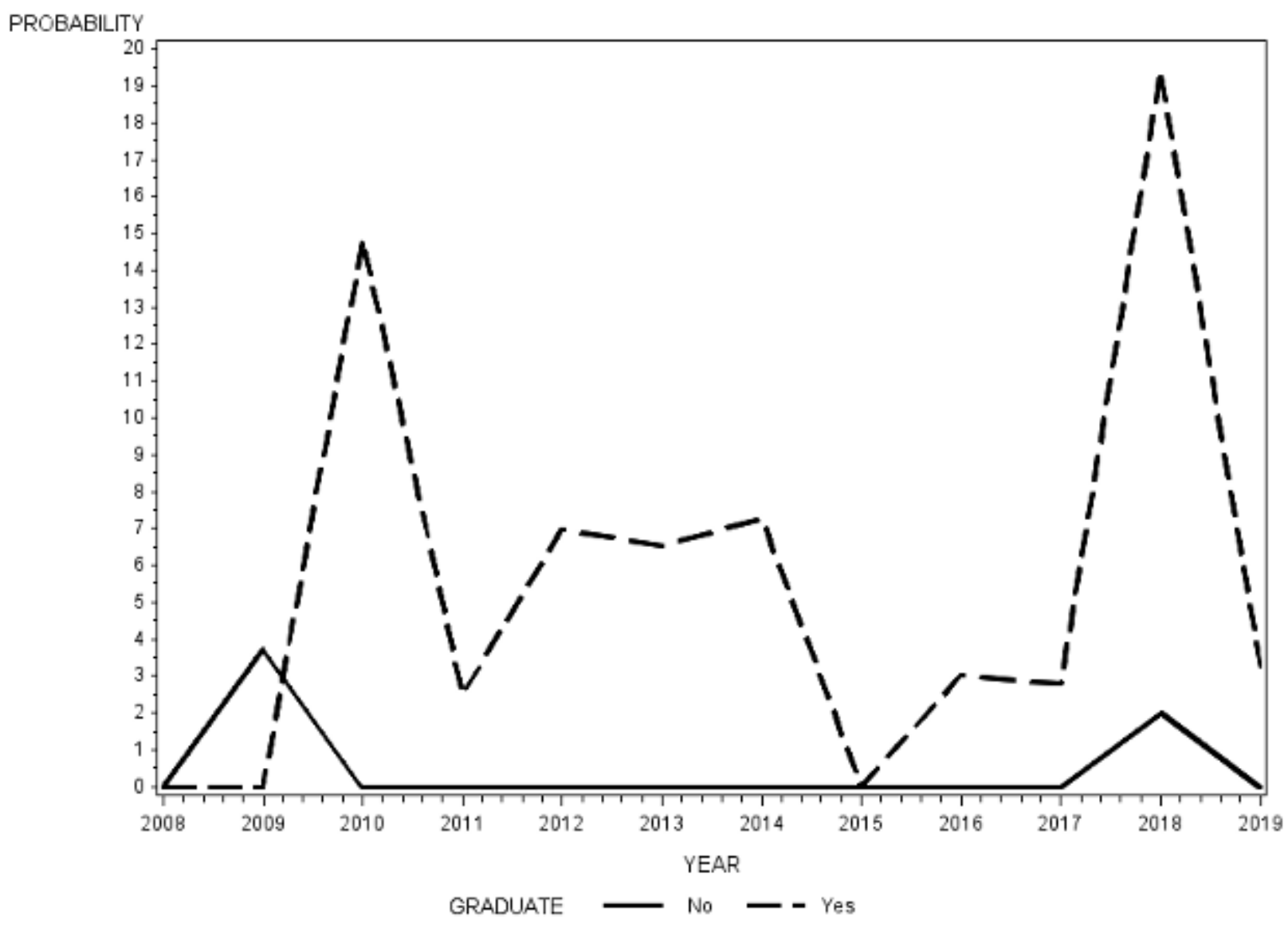

TABLE 2. Number of faculty members under observation and promotions by Institutional Faculty Development Course (IFDC) graduation status and year.

\begin{tabular}{|c|c|c|c|c|c|}
\hline & \multicolumn{2}{|c|}{ IFDC Graduate } & \multicolumn{2}{c|}{ Not an IFDC graduate } \\
\hline Year & $\begin{array}{c}\text { Number of } \\
\text { faculty under } \\
\text { observation }\end{array}$ & $\begin{array}{c}\text { Number of } \\
\text { promotions }\end{array}$ & $\begin{array}{c}\text { Number of } \\
\text { faculty under } \\
\text { observation }\end{array}$ & $\begin{array}{c}\text { Number of } \\
\text { promotions }\end{array}$ \\
\hline \hline 2008 & 14 & 0 & 15 & 0 \\
\hline 2009 & 19 & 0 & 27 & 1 \\
\hline 2010 & 27 & 4 & & 31 & 0 \\
\hline 2011 & 40 & 1 & 43 & 0 \\
\hline 2012 & 43 & 3 & 43 & 0 \\
\hline 2013 & 46 & 3 & 35 & 0 \\
\hline 2014 & 55 & 4 & & 36 & 0 \\
\hline 2015 & 55 & 0 & & 36 & 0 \\
\hline 2016 & 66 & 2 & 44 & 0 \\
\hline 2017 & 72 & 2 & 48 & 0 \\
\hline 2018 & 67 & 13 & 50 & 1 \\
\hline 2019 & 62 & 2 & 41 & 0 \\
\hline \hline
\end{tabular}


TABLE 3. Results of the repeated measures (longitudinal data) analysis from October 1, 2008, to October 1, 2019: 235 faculty members contributed a total of 1,015 records and the number of promotions was 36 . Adjusted odds ratios (OR) for being promoted to associate professor were calculated from a generalized estimating equations logistic regression model.

\begin{tabular}{|c|c|c|c|}
\hline Risk Factor & $\begin{array}{c}\text { Adjusted } \\
\mathrm{OR}^{\dagger}\end{array}$ & $\begin{array}{l}\text { 95\% Confidence } \\
\text { Interval }\end{array}$ & $\boldsymbol{P}$ \\
\hline \multicolumn{4}{|l|}{ Institutional Faculty Development Course } \\
\hline Graduate & 11.68 & $2.72-50.21$ & 0.001 \\
\hline Non-graduate & 1 & (Referent) & - \\
\hline One calendar year increase (2008-2019) & 1.09 & $0.95-1.26$ & 0.21 \\
\hline \multicolumn{4}{|l|}{ Age (years) } \\
\hline$\geq 40$ & 2.93 & $1.12-7.71$ & 0.03 \\
\hline$<40$ & 1 & (Referent) & - \\
\hline \multicolumn{4}{|l|}{ Sex } \\
\hline Female & 0.58 & $0.28-1.17$ & 0.13 \\
\hline Male & 1 & (Referent) & - \\
\hline \multicolumn{4}{|l|}{ Race-ethnicity } \\
\hline Asian & 2.02 & $0.89-4.59$ & 0.09 \\
\hline Other ${ }^{\ddagger}$ & 2.11 & $0.52-8.62$ & 0.30 \\
\hline White & 1.11 & $0.45-2.70$ & 0.83 \\
\hline Hispanic & 1 & (Referent) & - \\
\hline \multicolumn{4}{|l|}{ Discipline/Specialty } \\
\hline Medical school non-clinical department & 0.51 & $0.16-1.62$ & 0.25 \\
\hline $\begin{array}{l}\text { Medical school clinical department or } \\
\text { Nursing school }\end{array}$ & 1 & (Referent) & - \\
\hline \multicolumn{4}{|l|}{ Tenure status } \\
\hline Tenure track & 4.05 & $1.47-11.13$ & 0.007 \\
\hline Not tenure track & 1 & (Referent) & - \\
\hline
\end{tabular}

${ }^{\dagger}$ Each odds ratio is adjusted for the remaining variables that are found in the table.

$\ddagger$ This group is composed of 11 Blacks and 1 Native Hawaiian or Pacific Islander.

67 IFDC graduates were promoted, resulting in a probability of $19.4 \%$. During the same year, the probability of promotion was $2.0 \%$ in nongraduates (1/50).

ORs for being promoted are shown in Table 2. The 235 study subjects contributed a total of 1015 records to the longitudinal dataset. Each OR in Table 2 is adjusted for the remaining variables found in Table 3 . Three factors were associated with the outcome of promotion: IFDC graduation status, the faculty member's age, and tenure track status. IFDC graduates were more likely than non-graduates to be promoted: adjusted $\mathrm{OR}=11.68,95 \% \mathrm{Cl}: 2.72$ $50.21, P=0.001$. Faculty members who were 40 years of age or older had almost three times the odds of being promoted during the study period than faculty who were younger than 40 years: adjusted $\mathrm{OR}=2.93,95 \% \mathrm{Cl}: 1.12-7.71, \mathrm{P}=0.03$. Tenure track faculty had four times the odds of being promoted than non-tenure track faculty. 


\section{DISCUSSION}

Our observational study found a strong, positive correlation between graduating from our IFDC and promotion from assistant professor to associate professor. Additionally, a relationship between older age ( $\geq 40$ years) and increased odds of promotion was noted. Elevated odds for promotion were also noted for tenure track faculty. Faculty at our university who are on the tenure track have seven years to obtain tenure. Our multiple logistic regression analysis did not detect an association between the following variables and the odds of promotion: sex, race/ ethnicity, and discipline/specialty.

Previous evaluations of faculty development programs in medicine have tended to suffer from a small sample size, ${ }^{3-5}$ a lack of a comparison group, ${ }^{3,5}$ a reliance on subjective self-reported outcomes, ${ }^{3}$ and/or the inability to track faculty at the individual level longitudinally. ${ }^{7}$ Our longitudinal study addressed all four of these limitations.

We feel that multiple components of the IFDC had a beneficial impact on the likelihood of being promoted. First, IFDC graduates were familiarized with the promotion process at our institution, including the application timeline and required forms. Second, IFDC graduates were exposed to a network of possible mentors and resources at our institution.

In 2015, the Office of Faculty Development administered an anonymous survey to 74 IFDC graduates, of which $72 \%$ were clinical educators or medical educators. The majority of the survey respondents $(88 \%)$ noted that their participation in the IFDC helped them improve their teaching skills. A large proportion (66\%) of the respondents believed that their participation in the IFDC helped them improve their career planning, and 73\% replied Strongly Agree or Agree to the item, "Participation in IFDC had a positive impact on my department/institution." Forty-six percent of the survey respondents answered Yes when asked if participation in the IFDC helped them improve their research skills. In regard to leadership/administrative skills, $59 \%$ of the sample replied that participation in the IFDC helped them improve this particular set of skills. Of the clinical educators in the sample, $79 \%$ believed that the IFDC improved their teaching of clinical skills for students/ residents/fellows and junior faculty. Conducting qualitative research via focus groups composed of recent IFDC graduates may provide additional insight into the helpful aspects of the IFDC.

Chang et al. studied the impact of the following three national career development programs (CDP) on the promotion rates of women in academic medicine: The Early and Mid-Career Programs sponsored by the AAMC, and the Hedwig van Ameringen Executive Leadership in Academic Medicine sponsored by Drexel University. ${ }^{16}$ These investigators focused on faculty who had an appointment at a medical school that was accredited by the Liaison Committee on Medical Education. Their retrospective cohort study included 2719 CDP participants of the three aforementioned development programs, 12,865 non-participant women, and 26,810 men. Chang and colleagues found that CDP participants who were at the rank of assistant professor had three times the odds of being promoted to associate professor than non-CDP women faculty: adjusted $\mathrm{OR}=3.25$, 95\% Cl: 2.91-3.63.

The AAMC reported on the 10-year promotion rate of full-time faculty members who were first-time assistant professors at any point in time between 1967 and 1997. ${ }^{17}$ White faculty were found to have a higher promotion rate to associate professor than non-white faculty. In our investigation, we did not detect an association between the White race and the probability of promotion. Guevara et al. observed that the proportion of underrepresented minority faculty in U.S. allopathic medical schools increased modestly between 2000 and 2010; however, the existence of a faculty development program that targeted underrepresented minority faculty was not associated with greater underrepresented minority faculty promotion. ${ }^{7}$

Strengths of our study include long-term (11 years) follow-up at the individual level and the inclusion of a comparison group (the nongraduates). We were interested in estimating the population-averaged effect of graduating from the IFDC and hence used GEE. Had we been interested in estimating the subject-specific effect, fitting a mixed model (a random effects logistic regression model) would have been appropriate. ${ }^{11,18}$

Rather than having performed a longitudinal data analysis, we could have used the KaplanMeier method and Cox (proportional hazards) 
regression to identify predictors of the time to promotion. However, these survival analysis methods presume that censoring is noninformative. ${ }^{19}$ We avoided using these methods since informative censoring may have been present in our dataset. To clarify, some of the faculty who were lost to follow-up and hence right-censored may have realized that their probability of being promoted was low and chose to leave our institution.

While we controlled for several factors, a limitation of our study is that faculty who completed the IFDC were a select group. The IFDC OR may be confounded by destiny; individuals who were bound to succeed professionally whether or not they enrolled in a faculty development course may have been concentrated in the IFDC graduate arm of our observational study. However, given the very strong association that we detected (adjusted $\mathrm{OR}=11.68$ ), it is unlikely that confounding by an uncontrolled factor completely explains this result. ${ }^{20}$ Furthermore, we controlled for several factors including the faculty member's specialty. An additional limitation of our study was the inability to identify predictors of promotion from associate to full professor given the small numbers of faculty who experienced this outcome.

Large, long-term experimental trials (whether randomized or non-randomized) designed to compare the incidence of promotion in graduates of a faculty development program with the incidence in those who did not receive any form of institutional faculty development are not feasible or ethical. Even trials that aim to study two different forms of a faculty development program (e.g., a one-year program compared to a six-month program) would require a large sample size and six or seven years of follow-up. We believe few institutions would have the financial resources to accomplish this goal.

Future similar studies should strive to collect information on additional potential confounders, such as the amount of time faculty members regularly allocate for scholarly activities, attendance of seminars and grand rounds, the number and quality of mentors and sponsors that are available to the faculty, ${ }^{21}$ participation in national career development programs, ${ }^{16}$ and measures of personal and professional happiness, satisfaction, and faculty vitality. ${ }^{22}$ Finally, since the probability of being promoted may be influenced by institutional politics, other endpoints such as the h-index should be tracked longitudinally.

Triggered by the COVID-19 pandemic, our Office of Faculty Development in 2020 converted the IFDC to a strictly online program with a mix of asynchronous and synchronous sessions. ${ }^{23}$ Faculty members have many demands on their time. Moving from a face-to-face to an online (largely asynchronous) approach to delivering content allows participants greater flexibility as they engage in continuing education. We look forward to evaluating the impact of our new online program on multiple professional outcomes.

\section{CONCLUSION}

This observational study found that completion of the IFDC was strongly associated with promotion from assistant professor to associate professor at our health sciences center. Given the difficulties in conducting robust randomized trials, faculty development professionals typically rely on observational study designs, such as the retrospective cohort, as we did.

\section{DECLARATION OF CONFLICTING INTERESTS}

The authors declare that there is no conflict of interest.

\section{AUTHOR AFFILIATIONS}

1. Office of Faculty Development, Department of Obstetrics and Gynecology, Paul L. Foster School of Medicine, Texas Tech University Health Sciences Center El Paso, Texas

2. Office of the Provost, Texas Tech University Health Sciences Center, El Paso, Texas and College of Education Texas Tech University, Lubbock, Texas

3. Office of Institutional Research and Effectiveness, Department of Meddical Education, Texas Tech University Health mds.marshall.edu/mjm

(c) 2021 Marshall Journal of Medicine
Marshall Journal of Medicine

Volume 7 Issue 2 
Sciences Center, El Paso, Texas

4. Office of Faculty Development, Paul L. Foster School of Medicine, Texas Tech University Health Sciences Center, El Paso, Texas

5. Office of Institutional Research and Effectiveness, Texas Tech University Health Sciences Center, El Paso, Texas

\section{REFERENCES}

1. Alamoudi AA, El-Deek BS, Park YS, Al Shawwa LA, Tekian A. Evaluating the long-term impact of faculty development programs on MCQ item analysis. Med Teach. 2017;39:S45-S49.

2. Steinert Y, Mann K, Anderson B, et al. A systematic review of faculty development initiatives designed to enhance teaching effectiveness: A 10-year update: BEME Guide No. 40. Med Teach. 2016;38:769-786.

3. Armstrong EG, Barsion SJ. Using an outcomes-logic-model approach to evaluate a faculty development program for medical educators. Acad Med. 2006;81:483-488.

4. Gheihman G, Singh TA, Cooper CA, McKeon BA, Hirsh DA, Simpkin AL. Everyday resilience: equipping faculty with practical exercises to promote resilience among medical students. MedEdPORTAL. 2021;17:11076.

5. Chavda P, Mehta K, Patel T, Shringarpure K, Pandya C, Solanki D. A structured mentorship program for medical college faculty on health research. Med J Armed Forces India. 2021;77(Suppl 1):S180-S189.

6. Wolfe AD, Bhalala U. Marshall V. Building a local research symposium: the crossroads of scholarship, education, and faculty development. MedEdPORTAL. 2020;24;16:11048.

7. Guevara JP, Adanga E, Avakame E, Carthon MB. Minority faculty development programs and underrepresented minority faculty representation at US Medical Schools. JAMA. 2013;310:2297-2304.

8. Office of Faculty Development. Faculty development graduates, Texas Tech University Health Sciences Center El Paso. https://elpaso.ttuhsc.edu/som/ facdevelopment/Faculty Development Graduates.aspx. Accessed July 23, 2019.

9. Spencer J. Faculty development research: the 'state of the art' and future trends (Chapter
17). In: Steinert Y, ed. Faculty Development in the Health Professions: A Focus on Research and Practice. Dordrecht, The Netherlands: Springer Science+Business Media; 2014; 353374.

10. Kupesic Plavsic S, Mulla ZD. The essentials of a faculty development program in the setting of a new medical school. J Investig Med 2020;68:952-955.

11. Hu FB, Goldberg J, Hedeker D, Flay BR, Pentz MA. Comparison of population-averaged and subject-specific approaches for analyzing repeated binary outcomes. Am J Epidemiol. 1998;147:694-703.

12. Schober P, Vetter TR. Repeated measures designs and analysis of longitudinal data: if at first you do not succeed-try, try again. Anesth Analg. 2018;127:569-575.

13. Ziegler A, Vens M. Generalized estimating equations. Notes on the choice of the working correlation matrix. Methods Inf Med. 2010;49:421-425.

14. Hosmer D, Lemeshow S. Applied Logistic Regression. 2nd ed. New York, NY: John Wiley \& Sons, Inc.; 2000.

15. Hanley JA, Negassa A, Edwardes MD. GEE analysis of negatively correlated binary responses: a caution. Stat Med. 2000;19:715722.

16. Chang S, Guindani M, Morahan P, Magrane D, Newbill S, Helitzer D. Increasing promotion of women faculty in academic medicine: impact of national career development programs. J Womens Health (Larchmt). 2020;29:837-846.

17. Qi Liu C, Alexander H. Promotion rates for first-time assistant and associate professors appointed from 1967 to 1997. Analysis in Brief 2010. Association of American Medical Colleges. https://www.aamc.org/system/ files/reports/1/aibvol9 no7.pdf. Accessed October 21, 2020.

18. Kiernan K, Tao J, Gibbs P. Tips and Strategies for Mixed Modeling with SAS/STAT ${ }^{\circledR}$ Procedures, Paper 332-2012. SAS Global Forum 2012. https://support.sas.com/ resources/papers/proceedings12/332-2012. pdf. Accessed September 22, 2020.

19. Dey T, Mukherjee A, Chakraborty S. A practical overview and reporting strategies for statistical analyses of survival studies. Chest. 2020;158:S39-S48.

20. Schlesselman JJ. Assessing effects of confounding variables. Am J Epidemiol. 
1978;108:3-8.

21. Ayyala MS, Skarupski K, Bodurtha JN, González-Fernández M, Ishii LE, Fivush

$B$, Levine RB. Mentorship is not enough: exploring sponsorship and its role in career advancement in academic medicine. Acad Med. 2019;94:94-100.

22. Shah DT, Williams VN, Thorndyke LE, Marsh EE, Sonnino RE, Block SM, Viggiano TR. Restoring faculty vitality in academic medicine when burnout threatens. Acad Med. 2018;93:979-984.

23. Mulla ZD, Osland-Paton V, Rodriguez MA, Vazquez E, Kupesic-Plavsic S. Novel coronavirus, novel faculty development programs: rapid transition to eLearning during the pandemic. J Perinat Med.

2020;48: 446-449. 